\title{
Benign Chondrogenic Neoplasm
}

National Cancer Institute

\section{Source}

National Cancer Institute. Benign Chondrogenic Neoplasm. NCI Thesaurus. Code C8592.

A non-metastasizing cartilaginous matrix-producing neoplasm characterized by the presence of neoplastic chondrocytes. Representative examples include osteochondroma and chondroma. 